\title{
Biosaintifika
}

Journal of Biology \& Biology Education

http://journal.unnes.ac.id/nju/index.php/biosaintifika

\section{Characteristics of Superior Soybean Breeding Lines Tolerance to Rust (Phakopsora pachyrhizi)}

\author{
${ }^{\otimes}$ Alfi Inayati, Eriyanto Yusnawan \\ DOI: 10.15294/biosaintifika.v8i1.5081 \\ Indonesian Legumes and Tuber Crops Research Institute (ILETRI)
}

\section{History Article}

Received 16 February 2016

Approved 23 February 2016

Published 29 March 2016

\section{Keywords:}

soybean genotype; rust disease evaluation; resistance; tolerant

\begin{abstract}
Soybean rust caused by Phakopsora pachyrhizi is one of the most important diseases which limits soybean production. The aim of this study was to evaluate the resistance of 28 superior soybean lines and their tolerance to rust. The study was conducted at a screen house and arranged in a completely randomized design (CRD); three replications. All genotypes tested were artificially inoculated with P. pachyrhizi, and a set of un-inoculated genotypes was planted as a comparison. Number of pustules was recorded weekly, and resistant criteria was rated based on the International working group on soybean rust IWGSR method. Lesion color (LC), sporulation level (SL), number of uredia (NoU), frequency of pustule which had uredia, and yield were also recorded. Among 28 genotypes tested, only one was categorized as resistant and 2 genotypes were susceptible. Resistant genotypes had few pustules, lower AUDPC values, low disease severity, and Reddish Brown lesion type. Soybean rust affected yield components, i.e. number of intact pods and yield per plant. Yield loses due to rust in this study varied from 5-89\%, and the average was 51\%. The set of lines from Tanggamus pedigree showed more resistant to rust but less tolerant compared to Sinabung pedigree.
\end{abstract}

\section{How to Cite}

Inayati, A., \& Yusnawan, E. (2016). Characteristics of superior soybean breeding lines tolerancet to rust (Phakopsora pachyrhizi). Biosaintifika: Journal of Biology \& Biology Education, 8(1), 47-55.

(C) 2016 Semarang State University

Correspondence Author:

Kendalpayak KM 8, PO BOX 66, Malang East Java, Indonesia

p-ISSN 2085-191X

e-ISSN 2338-7610

E-mail: alfiinayati2@gmail.com 


\section{INTRODUCTION}

Asian soybean rust (ASR) caused by Phakopsora pachyrhizi is one of the most important pathogens which limits soybean production. The ASR causes significant yield loss up to $80 \%$ under heavily infection, depending on the susceptibility of the genotype (Twizeyimana et al., 2009). $P$. pachyrhizi infection also causes premature defoliation that effects the number of intact pods and yield reduction (Kumudini et al., 2008), reduces number of pods and seed sizes (Li et al., 2010). Early infection may not devastate the crops, but may reduce the overall yield more than that of the late infection.

The availability of resistant or tolerant cultivars is a key component of rust integrated control (Twizeyimana et al., 2009; Hartman et al., 2011). However, soybean breeding for resistance to soybean rust is complicated because of the lack of information about the host-parasite interaction (Pham et al., 2010) and the limitation of parent material resistant to rust. Tolerant cultivars could be one of the alternative choices to reduce yield loss on soybean caused by the rust disease. Tolerance can be defined as the plant capacity to resist the pathogen development, without significant reduction in yield or quality of the product (Scafer, 1971; Politowski \& Browning, 1978). The best technique to develop new cultivars which are resistant to rust is to screen the available germplasm and to create pedigree from the existing cultivars and genotypes.

There are some important parameters to classify the tolerance of soybean to rust. Araujo \& Vello (2010) mentioned that the intensity of pathogen sporulation and periodical severity assessment were important parameters for the classification of genotypes into tolerant or susceptible to rust. Moreover, Hartman et al., (2011) said that the number of uredinia per $\mathrm{cm} 2$ was also important besides the lesion color and types (Yamanaka et al. 2010). Sometimes, response of soybean to rust was ambiguous or partially resistant as a result of genotype response to the environmental factors, i.e. temperature, humidity, and plant's physiological factors. The variability in genotype reaction was also influenced by the interaction between the host genotype, soybean rust pathotype, and environmental conditions (Slaminko et al., 2008). Hartman et al., (2011) reported that there was very high virulence variability in ASR population especially in Asia as the center of origin and diversity of both the rust pathogen and its host soybean.

In Indonesia, soybean breeding for resis- tance to rust may be complicated due to lack of knowledge of the host-pathogen interaction and environmental factor. Therefore, non-host specific resistance and tolerant cultivars could be an alternative. Indonesian Legume and Tuber Crops Research Institute (ILETRI) have some superior breeding lines derived from superior cultivars, namely Tanggamus (Tgm), Anjasmoro (Anj), Burangrang (Brg), Sinabung (Sin), Argomulyo (Arg), and Malabar (Mal) to improve the superiority of its parental. This study aimed to evaluate the resistance of soybean lines against soybean rust and its potential loss due to this disease. This information is crucial for supporting data in releasing a new variety and also important to develop good agricultural practices suitable for cultivar characteristics.

\section{METHODS}

Twenty five soybean genotypes consisted of 23 lines and two cultivars (Anjasmoro and Grobogan) were planted at a screen house to evaluate its resistance to soybean rust. Soybean seeds were sowed in plastic pots with $5 \mathrm{~kg}$ mixtures of soil and cow manure $(2: 1 \mathrm{v} / \mathrm{v})$ with NPK fertilizers of 1:2:2 (w/w/w) (5 grams per pot). Two $\mathrm{ml}$ $1^{-1}$ of Captan was applied at 14 and 21 days after planting (dap) to reduce soil borne pathogens. The average temperatures were recorded during the study $\left(25-28^{\circ} \mathrm{C}\right)$ as well as relative humidity (80-85\%).

Artificial inoculation with $P$. pachyrhizi urediospores suspension at concentration of 104 spore ml-1 was conducted twice, at 21 and 28 dap. The uredia was harvested from susceptible variety, Ringgit, which was planted four weeks prior to the study. Prior to inoculation, infected leaves with mature urediospores were placed on wet sterile papers in trays to maintain the humidity. The infected leaves then were incubated for 24 hours at room temperature. Inoculum was prepared by suspending the urediospores in sterile water. As many as $20 \mu 1$ Tween 20 was added in the suspension and mixed well and then filtered through a cheesecloth. The urediospores were sprayed on the abaxial surface of the leaves in the evening using hand sprayer. The experiment was arranged in a completely randomized design (CRD) with three replications. Every genotype was planted in six pots and a pot consisted of two plants. A separate experiment was conducted without artificial inoculation as a check.

Response of soybean genotype to rust was evaluated starting from seven days after inoculation (dai). Numbers of pustules were recorded 
weekly. The ASR infection level and soybean genotype resistance were rated using the modified three digits of International Working Group of Soybean Rust (IWGSR). Disease severity was also rated at 49 dap based on the leaf area covered by the P. pachyrhizi according to Godoy et al., (2006) methods (Figure 1).

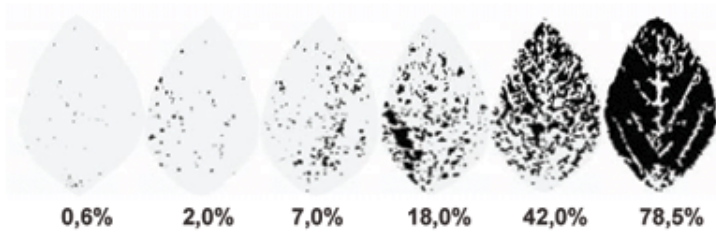

Figure 1. Diagrammatic scale of soybean rust severity (percentage of leaf area infected) (Godoy et al. 2006)

Lesion color (LC), sporulation level (SL), number of uredia per lesion (NoU), and frequency of lesions which had uredinia (\% LU) were also evaluated and classified into six categories in accordance to the method of Yamanaka et al. (2010), where 1 (very dark) to 6 (very light). The $\mathrm{SL}$ of each lesion was classified into 0 (no spores) to 3 (abundant spores) (Figure 2). Area Under Disease Progress Curve (AUDPC) was calculated according to Simko \& Piepho (2012) to estimate the disease progress on each genotype.

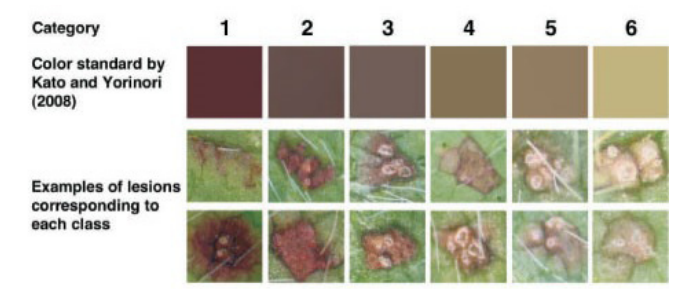

B

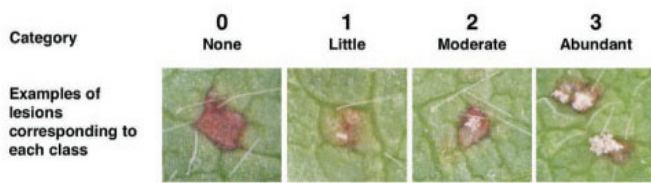

Figure 2. Standards of lesion color (A) and sporulation level (B) (Yamanaka et al., 2010)

Yield components, including number of pods, number of empty pods and the weight of seed per plant were recorded from both inoculated and un-inoculated sets. Stress index (SI) was calculated using formula of SI =

$$
\left(1-\frac{\text { mean of yield on inoculated plant }}{\text { mean of yield on un- inoculated plant }}\right) .
$$

Tolerance of soybean genotypes to rust was assessed from the percentage of yield on un-inoculated plants and yield from inoculated plants. (Tolerance =

Yield on un-inoculated plant-yield on inoculated plant Yield on un-inoculated plant

$\times 100)$ and rust tolerance index $(\mathrm{RTI}=$ yield on inoculated plant / yield on un-inoculated plant) as formulated by Kawuki et al. (2003).

\section{RESULTS AND DISCUSSION}

Soybean rust symptom was signed by the appearance of $P$. pachyrhizi pustule on the abaxial surface of leaf started varied from V2 stage to V6 depending on the genotypes. Average number of pustules at the first observation, 7 days on Argomulyo/Sinabung (Arg/Sin) pedigree was the highest (26 pustules $\mathrm{cm}-1)$. All Sinabung pedigrees (Sin/Arg, Sin/Mal, Mal/Sin, L.Jat/Sin, and $\mathrm{Arg} / \mathrm{Sin}$ ) had relatively higher number of pustule compared to that of Tanggamus lines. These lines had a heavy pustule density since the number of pustules was more than 16 pustules $\mathrm{cm}-2$. In contrast, all Tanggamus pedigree lines (Tgm/Anj and Tgm/Brg) had less pustules and been categorized as light to medium pustule density which had less than 9 pustules $\mathrm{cm}-2$ except Tgm/Anj-743.

The pustule number of genotypes tested did not consistently show the same trend on weekly observation. At 21 days, when data recorded were used as justification for resistant criteria, the number of pustules on all genotypes did not show significant differences, it varied from 3 to 8 pustules $\mathrm{cm}-2$. However, P. pachyrhizi pustules had covered almost all the leaves (Table 1).

In general, the increase of the number of pustules was in line with the plant's age and the duration of infection. In this study, the numbers of pustules did not constantly increase over period of time due to the number of pustules. This was also influenced by the environmental factors such as temperature (canopy temperature), humidity (leaf wetness), and light. Medeiros et al., (2008) stated that in an experiment conducted in South Africa, the number of pustules per lesion, as well as lesion size increased with the increase of leaf wetness duration at $85 \%$ and $95 \% \mathrm{RH}$, and the temperature was $21-24^{\circ} \mathrm{C}$. The average temperature during this study was $25-28^{\circ} \mathrm{C}$ and $80-85 \%$ of relative humidity which was less favorable for pustule growth and development.

The development of rust disease was not only influenced by the increase in the number of pustule, but also the position of pustule or uredia on the leaves. In this study, the pustule observed at the third upper side of plant since 2 weeks after inoculation represented the development of rust 
Table 1. Numbers of pustules, rust severity (\%), IWGSR score, and IWGSR resistant criteria of soybean breeding lines

\begin{tabular}{|c|c|c|c|c|c|c|c|}
\hline \multirow[t]{2}{*}{$\begin{array}{l}\text { Breeding line/ } \\
\text { genotype }\end{array}$} & \multicolumn{4}{|c|}{$\begin{array}{l}\text { Numbers of } \\
\text { pustules } \mathrm{cm}^{-2} \text { at } \\
\ldots \text { dai }\end{array}$} & \multirow[t]{2}{*}{$\begin{array}{l}\text { IWGSR } \\
\text { score at } \\
21 \text { dai }\end{array}$} & \multirow[t]{2}{*}{$\begin{array}{l}\% \text { rust } \\
\text { severity }\end{array}$} & \multirow[t]{2}{*}{$\begin{array}{l}\text { IWGSR } \\
\text { resistant } \\
\text { criteria }\end{array}$} \\
\hline & 14 & 21 & 28 & 35 & & & \\
\hline Tgm/Anj-743 & 7 & 6 & 6 & 8 & 222 & 5.9 & $\mathrm{R}$ \\
\hline Tgm/Anj-744 & 4 & 4 & 10 & 7 & 322 & 1.7 & MR \\
\hline Tgm/Anj-773 & 7 & 4 & 7 & 9 & 232 & 7.3 & MR \\
\hline Tgm/Anj-778 & 4 & 4 & 10 & 14 & 332 & 4.9 & MS \\
\hline Tgm/Anj-780 & 5 & 5 & 10 & 3 & 322 & 3.2 & MR \\
\hline Tgm/Anj-784 & 4 & 3 & 7 & 6 & 322 & 0.6 & MR \\
\hline Tgm/Anj-790 & 4 & 5 & 11 & 4 & 322 & 1.7 & MR \\
\hline Tgm/Anj-795 & 6 & 8 & 8 & 6 & 322 & 2.5 & MR \\
\hline Tgm/Anj-847 & 6 & 3 & 9 & 3 & 322 & 1.5 & MR \\
\hline Tgm/Anj-871 & 5 & 3 & 8 & 4 & 322 & 1.1 & MR \\
\hline Tgm/Anj-908 & 6 & 9 & 11 & 10 & 232 & 1.5 & MR \\
\hline Tgm/Anj-909 & 5 & 6 & 5 & 5 & 322 & 3.2 & MR \\
\hline Tgm/Brg-558 & 4 & 4 & 6 & 7 & 322 & 5.3 & MR \\
\hline Tgm/Brg-565 & 8 & 8 & 15 & 5 & 322 & 1.1 & MR \\
\hline Tgm/Brg-599 & 8 & 6 & 6 & 8 & 322 & 3.0 & MR \\
\hline Tgm/Brg-530 & 5 & 8 & 5 & 5 & 322 & 3.0 & MR \\
\hline Sin/Arg-8 & 14 & 6 & 6 & 7 & 323 & 11.7 & MR \\
\hline Sin/Mal-16 & 19 & 5 & 4 & 11 & 333 & 9.0 & MS \\
\hline Sin/Mal-19 & 30 & 9 & 6 & 10 & 333 & 7.3 & MS \\
\hline Arg/Sin-34 & 26 & 8 & 7 & 7 & 323 & 10.7 & MR \\
\hline Arg/Sin-47 & 19 & 6 & 2 & 9 & 333 & 11.7 & MS \\
\hline Arg/Sin-52 & 33 & 5 & 6 & 10 & 333 & 11.3 & MS \\
\hline Mal/Sin-66 & 17 & 5 & 4 & 9 & 333 & 9.7 & MS \\
\hline Mal/Sin-68 & 19 & 5 & 10 & 9 & 323 & 9.0 & MR \\
\hline L.Jat/Sin-85 & 18 & 7 & 5 & 22 & 343 & 15.7 & $\mathrm{~S}$ \\
\hline Arg/Sin-98 & 29 & 4 & 5 & 9 & 323 & 6.7 & MR \\
\hline Anjasmoro & 18 & 5 & 5 & 12 & 333 & 5.7 & MS \\
\hline Grobogan & 21 & 7 & 7 & 24 & 343 & 25.7 & $\mathrm{~S}$ \\
\hline
\end{tabular}

disease which was relatively fast, in contrast to the rust severity and the number of pustules on all genotypes tested which were relatively low. The upper third of the leaf canopy had been infected by $P$. pachyrhizi since 14 days, and all pustules were sporulated, causing the increase in infection site and the reduction of latent period. According to IWGSR resistant criteria, of the 28 genotype tested, only 1 breeding line (Tgm/Anj 743) was categorized as resistant $(\mathrm{R})$ to the rust. 19 genotypes were moderately resistant, and the other 6 genotypes were moderately susceptible, whereas
2 genotypes (L.Jat/Sin-85 and Grobogan variety) were susceptible. None of the genotype tested was categorized as immune (Table 1).

Rust severity illustrated by leaf area covered by the P. pachyrhizi pustules showed light to medium, and the infection rates varied from 0.6 to $25.7 \%$ (Table 1). The average of rust severity on susceptible genotypes was $20.7 \%, 8.5 \%$ on moderately susceptible genotypes, and $5.9 \%$ on resistant genotypes which represented the relatively slow expansion of urediospores. The severity of the rust on Sinabung pedigrees was heavier than 
that of the Tanggamus pedigrees even though the highest was on Grobogan cultivar. Rust severities on Sinabung pedigrees were more aggressive, and the pustules covered broader leaf area. In this case, the effect of genetic materials which were partially resistant played an important role. Genotypes which were partial resistant expressed incomplete resistance which were characterized by pathogen colonization. This may occur in inoculated plants, but the extent of colonization was limited compared to that on fully susceptible genotypes, non-pathotype specific, and reduced selection pressure by allowing limited pathogen propagation to occur (Hartman et al., 2011).

Three lesion types were observed on all breeding lines including reddish brown (RB), Tan, and mixtures of RB and Tan (Figure 3). Most of genotype tested had mixed RB and Tan lesion color while most of genotypes tested (68\%) were moderately resistant to rust. In contrast to the study conducted by Kato \& Yorinori (2008), resistant genotypes have RB lesion, and susceptible genotypes have Tan lesion, and some have mixture of RB and Tan.

Responses of all genotypes tested to rust also varied in terms of the lesion types, lesion color, sporulation levels, number of uredia, and frequency of lesions with uredia (Fig 4). The lesion color of the genotypes tested varied from very dark (1) to light (5), depending on their parental. Most of Tanggamus pedigrees had light lesion color (4 to 5 color standard categories) and Sinabung pedigrees have darker color lesion, categorize as 2 to 3 on Kato \& Yorinori color standard (Figure 4a). Sporulation level on all genotypes tested ranged from none (0) to abundant (3). Eleven genotypes had moderate sporulation level (scored as 0-2 and 1-2). 11 genotypes had abundant sporulation (scored as 1-3), and only 6 genotypes had less sporulation (Figure $4 b$ ). Number of uredia varied from 0 to 5 per pustule. The highest num- ber of uredia on Sinabung pedigrees was 5 , whereas on Tanggamus pedigrees were only 3 uredia per pustule (Figure 4c). In line with the number of uredia, frequency of lesion which had uredinia on Tanggamus pedigrees was lower than that on Sinabung pedigrees. Frequency of lesion which had uredinia on Tanggamus pedigree varied from $47 \%$ to $100 \%$, and the average was $78 \%$. On the other hand, frequency of lesion which had uredinia on Sinabung pedigree varied from $68 \%$ to $100 \%$, and the average was $95 \%$ (Figure $4 \mathrm{~d}$ ).

Lesion color is known to be controlled by resistant genes, and it is important to observe the lesion color when selecting the resistant genotypes. In this study, it was difficult to group all genotypes tested into resistant criteria based on its lesion color due to the large variation among samples in every genotype. Yamanaka et al., (2010) explained LC was easily influenced by environmental factors, and it has a low correlation with other resistant characters including SL, NoU, and \% LU, so it is important to complete LC data with SL, NoU, and \% LU data. Spore production was considered to be more important to be identified because it represented the potency of urediospores to infect the crop. The higher level of sporulation, the bigger chance of disease to spread throughout the crop was. The chance of pathogen to spread out was also supported by the higher number of uredia and the frequency of lesions which had uredia. Most of Sinabung pedigrees were categorized as moderately susceptible genotypes which had higher SL, NoU, and $\%$ LU compared to those of Tanggamus pedigrees. It was illustrated that susceptible genotypes had higher SL, NoU, and \% LU than resistance genotypes.

Disease progress and rust development over period of time could be represented by AUDPC value. Area under Disease Progress Curve (AUDPC) values calculated from the number of

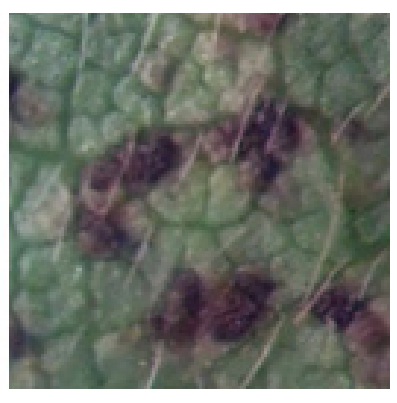

(a)

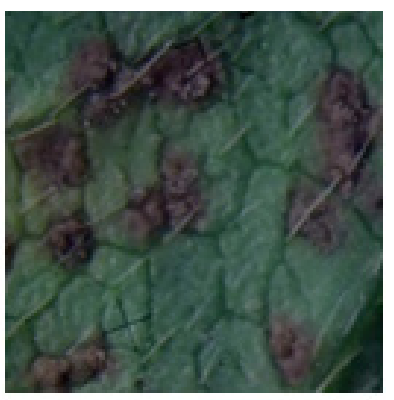

(b)

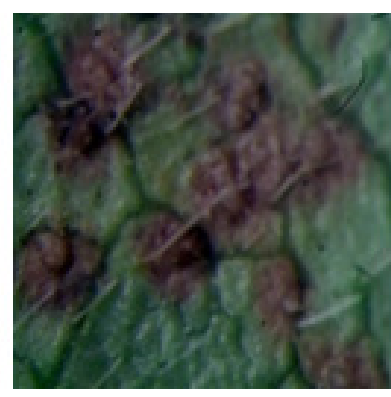

(c)

Figure 3. Lesion type of ASR on the two sets of the soybean breeding lines, (a) Reddish Brown, (b) Tan, and (c) mixture between Reddish Brown and Tan 


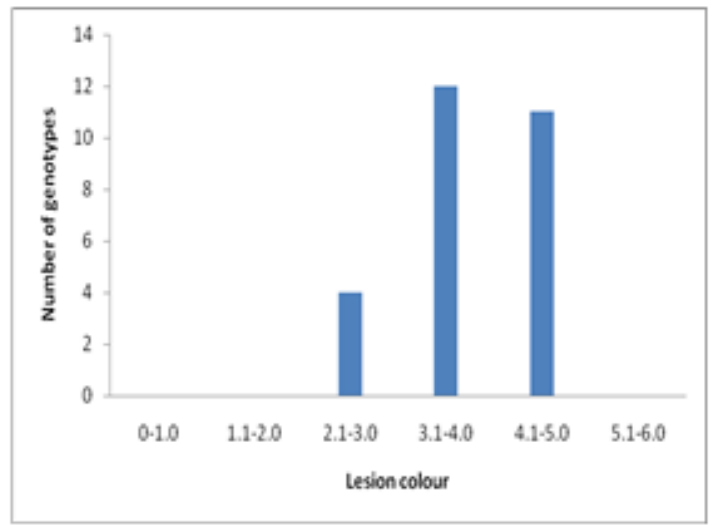

(a)

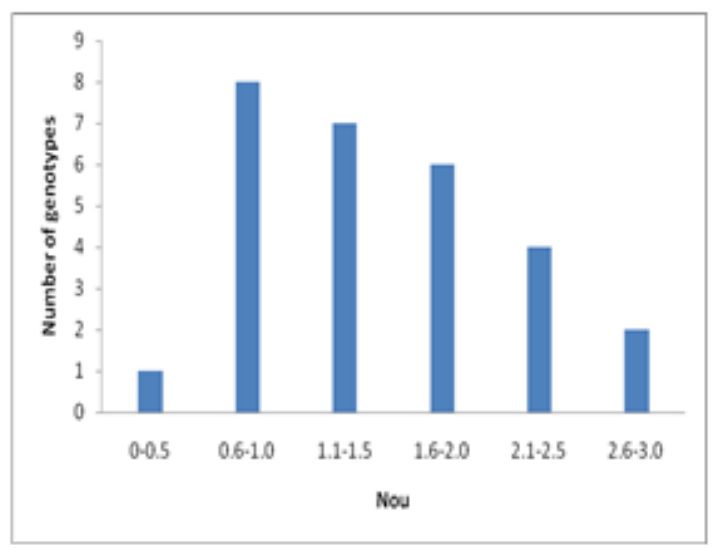

(c)

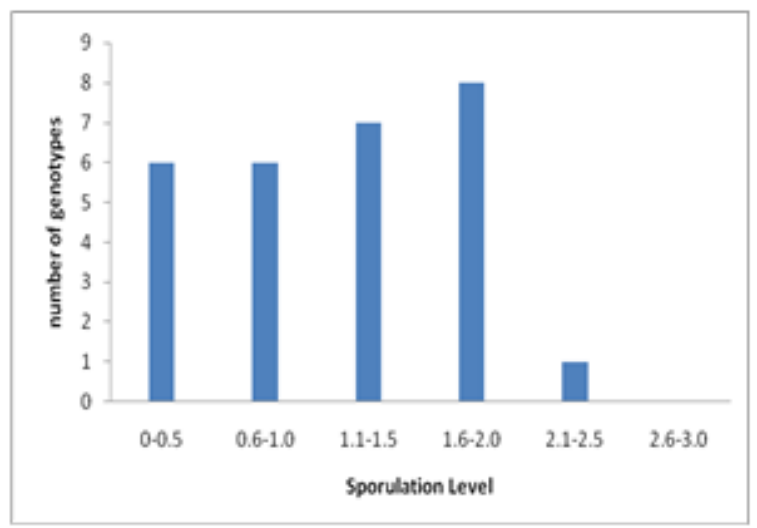

(b)

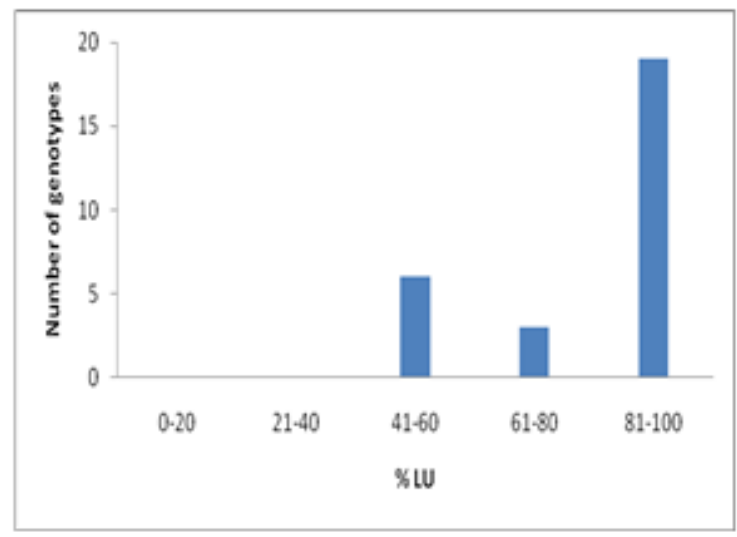

(d)

Figure 4. (a) Lesion color (LC), (b) sporulation level (SL), (c) numbers of uredia per pustule (NoU), and (d) frequency of lesions that had uredinia $(\% \mathrm{LU})$

pustules per $\mathrm{cm} 2$ ranged from 11.5 to 390.9 (Table 2). Susceptible genotypes had higher AUDPC value than that of the resistance genotypes. However, not all the susceptible breeding lines had high AUDPC values as observed in Anjasmoro cultivar. The positive correlations were observed between AUDPC and sporulation level $(r=0.5)$, between AUDPC and number of pustules $(r=$ 0.6 ), and between AUDPC and disease severity $(\mathrm{r}=0.4)$. These correlations showed that rapid advance of the disease was caused by the increase of sporulation which resulted in increasing of the number of pustules and more secondary infection sources. In line with study conducted by Cherif et al., (2010) and Maphosa, Talwana, \& Tukamuhabwa (2013) AUDPC was related to factor effected resistance to rust such as lesion number, sporulation, and disease severity even tough, sometimes AUDPC value was ambiguous due to the fact that it was highly influenced by the environment (Mueller et al., 2009; Cherif et al., 2010; ). In this study, the highest AUDPC values did not represent the highest rust severity, the highest pustules, and the highest sporulation, and sometimes the low AUDPC occurred in genotypes which had high sporulation and high disease severity.

Soybean rust infection reduced yield and yield components such as number of intact pods, number of empty pods, and weight of seed per plant (Table 2). Number of intact pods per plant varied from 6 to 22 pods. The average number of intact pods on the susceptible genotypes was lower than that of resistant genotypes. Number of intact pods on resistant and moderately resistant genotypes varied from 11 to 22 pods per plant, and those of the susceptible varied from 6 to 20 pods per plant. Besides having number of intact pods, the number of empty pods was also recorded, and the result showed that the average number of empty pods per plant on susceptible genotypes $(0.9)$ was higher than that on resistant genotypes (0.7).

Average yield per plant was low due to the rust infection. Stress amount caused by rust infection which was illustrated by SI was 0.61 . It me- 
Table 2. The Area under Disease Progress Curve (AUDPC) value, number of pods, number of empty pods, and yield per plant of two sets soybean breeding lines

\begin{tabular}{|c|c|c|c|c|c|c|c|}
\hline \multirow[t]{2}{*}{$\begin{array}{l}\text { Breeding line/ } \\
\text { genotype }\end{array}$} & \multirow[t]{2}{*}{ AUDPC } & \multicolumn{2}{|c|}{$\begin{array}{c}\text { Number of } \\
\text { pods per plant }\end{array}$} & \multicolumn{2}{|c|}{ Yield per plant } & \multicolumn{2}{|c|}{$\begin{array}{l}\text { Number of } \\
\text { empty pods per } \\
\text { plant }\end{array}$} \\
\hline & & inoc & Un-inoc & inoc & Un-inoc & Inoc & Un-inoc \\
\hline Tgm/Anj-743 & 40.67 & 21.3 & 27.7 & 3.1 & 11.0 & 0.9 & 0.7 \\
\hline Tgm/Anj-744 & 54.50 & 19.0 & 25.3 & 2.4 & 10.6 & 1.0 & 0.3 \\
\hline Tgm/Anj-773 & 62.17 & 19.8 & 29.7 & 2.5 & 9.6 & 1.3 & 1.3 \\
\hline Tgm/Anj-778 & 143.00 & 17.4 & 30.3 & 2.4 & 21.2 & 1.3 & 1.7 \\
\hline Thm/Anj-780 & 60.67 & 13.5 & 18.0 & 1.5 & 8.7 & 1.6 & 1.7 \\
\hline Tgm/Anj-784 & 11.50 & 18.1 & 26.3 & 3.1 & 15.2 & 1.0 & 0.0 \\
\hline Tgm/Anj-790 & 36.67 & 14.1 & 40.7 & 2.6 & 17.5 & 1.0 & 1.0 \\
\hline Tgm/Anj-795 & 20.00 & 18.0 & 22.3 & 2.5 & 9.3 & 0.8 & 0.7 \\
\hline Tgm/Anj-847 & 22.83 & 17.9 & 22.3 & 3.3 & 10.9 & 1.9 & 1.7 \\
\hline Tgm/Anj-871 & 20.67 & 15.3 & 17.3 & 2.8 & 8.0 & 2.3 & 1.3 \\
\hline Tgm/Anj-908 & 108.50 & 14.0 & 24.7 & 2.5 & 11.9 & 1.3 & 0.7 \\
\hline Tgm/Anj-909 & 14.33 & 16.1 & 22.0 & 2.7 & 11.2 & 1.1 & 1.0 \\
\hline Tgm/Brg-558 & 15.00 & 15.6 & 20.0 & 2.8 & 10.0 & 1.1 & 1.3 \\
\hline Tgm/Brg-565 & 91.83 & 13.9 & 14.0 & 2.3 & 7.7 & 1.2 & 1.0 \\
\hline Tgm/Brg-599 & 80.17 & 10.9 & 27.3 & 2.1 & 12.1 & 1.2 & 0.7 \\
\hline Tgm/Brg-530 & 18.33 & 19.4 & 25.0 & 3.4 & 13.7 & 1.3 & 0.7 \\
\hline Sin/Arg-8 & 90.46 & 18.4 & 27.0 & 5.9 & 6.2 & 0.6 & 2.7 \\
\hline Sin/Malabar-16 & 204.67 & 17.3 & 31.0 & 5.6 & 6.1 & 0.9 & 2.7 \\
\hline Sin/Malabar-19 & 390.96 & 19.9 & 41.3 & 5.2 & 7.1 & 0.8 & 3.3 \\
\hline Arg/Sing-34 & 181.00 & 18.4 & 30.7 & 6.0 & 6.4 & 1.3 & 2.0 \\
\hline Arg/Sin-47 & 115.79 & 16.5 & 28.7 & 5.5 & 6.9 & 0.9 & 1.7 \\
\hline Argo/Sin-52 & 280.50 & 15.3 & 32.7 & 5.5 & 6.0 & 1.0 & 2.7 \\
\hline Mal/Sin-66 & 180.33 & 15.0 & 20.7 & 5.1 & 6.9 & 1.1 & 2.0 \\
\hline Mal/Sin-68 & 191.63 & 14.7 & 24.7 & 6.0 & 5.1 & 0.8 & 3.0 \\
\hline L.Jat/Sin-85 & 196.17 & 16.4 & 29.0 & 5.4 & 6.2 & 1.3 & 2.3 \\
\hline Arg/Sin-98 & 110.33 & 16.6 & 25.3 & 6.2 & 5.8 & 0.9 & 3.0 \\
\hline Anjasmoro & 81.83 & 5.5 & 27.7 & 1.2 & 5.4 & 0.7 & 1.3 \\
\hline Grobogan & 217.50 & 8.4 & 19.0 & 3.6 & 5.9 & 0.8 & 2.0 \\
\hline
\end{tabular}

$\mathrm{R}=$ resistant, $\mathrm{MR}=$ Moderately Resistant, $\mathrm{S}=$ Susceptible, $\mathrm{MS}=$ Moderately Susceptible

ans that the disease stressor was relatively high. The yield varied from 2.7 to 10.6 grams per plant on the inoculated set, and it was higher on the un- inoculated set. The yield varied from 7 to 20.7 grams per plant. Yield loses due to rust in this study varied from $5-89 \%$, and the average was $51 \%$. Yield loss on Sinabung pedigree was lower than that on Tanggamus pedigree, the average of yield loss on Sinabung pedigree was 9\%, and yield loss on Tanggamus pedigree was $76 \%$. Disease severity, as measured by the AUDPC, was positively correlated to the yield loss $(r=0.7)$. In most
Tanggamus pedigrees with low AUDPC values, a big differences in yield were observed among infected and uninfected crops; however, not all Sinabung pedigrees which had higher AUDPC value had lower yield losses. As described above, AUDPC value was highly influenced by genotype $\mathrm{x}$ environment interactions. However, in this study the influence of genotype factor was dominant since all breeding lines were cultivated in the same environment. The large variation was found on the AUDPC value. However, lack association was noticed between the area under the disease 
and the resistance of the genotypes tested to rust.

Rust Tolerance Index value on Tanggamus pedigree varied from 0.11 to 0.35 , lower than that of Sinabung which was from 0.73 to 1.19 . Three dimensional diagram illustrated based on RTI, yield in stress plant, and yield potential was shown in Figure 5.

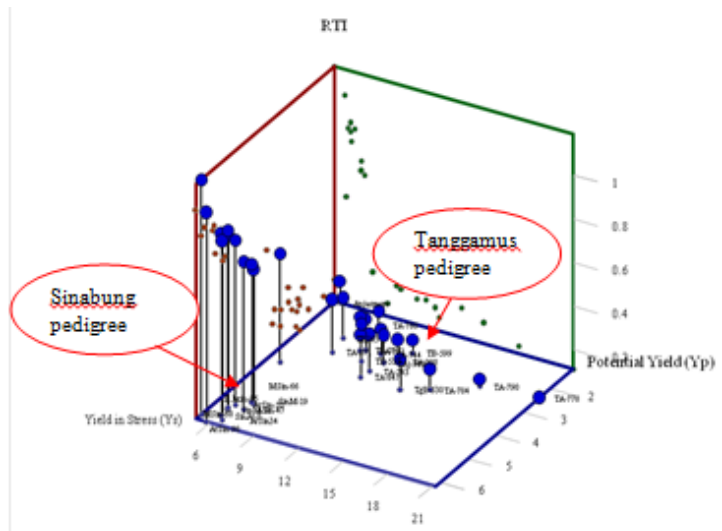

Figure 5. Three dimensional diagrams illustrated based on RTI, yield in stress plant, and yield potential on soybean lines

On three dimensional diagram, all Tanggamus pedigrees were grouped into one group, which was separated from Sinabung pedigrees, whereas existing cultivars (Anjasmoro and Grobogan) were in the same group with the Tanggamus pedigrees. This diagram illustrated that tolerance of Tanggamus pedigree are relatively lower than Sinabung pedigrees. Tolerance to soybean rust in genotypes tested was shown by Sinabung pedigrees, which had yield loss which was lower due to rust. It means that the yield on rust infected plants was not significantly different with those on un-infected plants. As described by Jarvie (2009) tolerance is genotypes with yield on stressed plant which is not significantly different with it on healthy plant, as it implies that genotypic adaptation to that environment. In a case of more severe disease symptoms, breeding lines which were categorized as tolerant showed a lower reduction of yield.

Tolerance to rust cultivar could be an alternative since resistant cultivar is difficult to develop due to big variability in genotype $\mathrm{x}$ environment interaction, rust pathogen pathotype, and the lack of information about genetic materials which contain resistant genes. In this study, the set of breeding lines from Tanggamus pedigrees showed more resistant to rust compared to the set of Sinabung pedigrees, nevertheless, the yield loses on Tanggamus pedigrees were higher than those of Sinabung pedigrees. Breeding lines crossed from Tanggamus and Sinabung cultivars could be proposed to develop new cultivars resistant to rust.

Soybean rust has widely spread in Indonesia, but the study of characteristic of genotypes resistant and tolerant to rust is still limited. The variation in reaction patterns of Indonesian soybean genotypes would be different if it was compared with soybean from other places, representing that they might contain new sources of rust resistance that useful to create a new cultivar resistance to rust.

\section{CONCLUSION}

Resistance to moderately resistant soybean genotypes have characterized by low number of pustules, lower AUDPC values, low disease severity and had Reddish Brown lesion type. Among 28 genotypes tested, only one genotype (Tgm/ Anj-743) was categorized as resistant, whereas 19 genotypes; most of them were Tanggamus pedigree, were moderately resistant. 6 genotypes; most of them were Sinabung pedigree, were categorized as moderately susceptible, and 2 genotypes (L.Jat/Sin-85 and Grobogan) were susceptible. Tolerant genotypes showed by Sinabung pedigree (Sin/Arg-8, Sin/Malabar-16, Sin/Malabar-19, Arg/Sing-34, Arg/Sin-47, Argo/Sin-52, Mal/ Sin-66, Mal/Sin-68, L.Jat/Sin-85, and Arg/ Sin-98) had lower yield loses and higher tolerant index. Even though the set of superior breeding lines from Tanggamus pedigree showed more resistant to rust it was less tolerant compared to Sinabung pedigree. Breeding lines crossed from Tanggamus and Sinabung cultivars could be proposed to generate new cultivar that was resistant to rust.

\section{ACKNOWLEDGMENT}

We wish thank to Dr. Titik Sundari, Dr. M.Muchlish Adie, and Dr. Heru Kuswantoro for their permission to use genetic materials used in this study.

\section{REFFERENCES}

Araujo, M. M. De, \& Vello, N. A. (2010). Characterization of soybean genotypes for Asian soybean rust reaction. Crop Breeding and Applied Biotechnology (Online), 10(3), 197-203. http:// doi.org/10.1590/S1984-70332010000300003

Cherif, M., Rezgui, S., Devaux, P., \& Harrabi, M. (2010). Genotype $\times$ environment interactions and heritability of quantitative resistance to net 
blotch in Tunisian barley. Journal of Plant Breeding and Crop Science, 2(5), 110-116.

Godoy, C. V., Koga, L. J., \& Canteri, M. G. (2006). Diagrammatic scale for assessment of soybean rust severity. Fitopatologia Brasileira, 31(43), 63-68. http://doi.org/10.1590/S0100 41582006000100011

Hartman, G. L., Hill, C. B., Twizeyimana, M., Miles, M. R., \& Bandyopadhyay, R. (2011). Interaction of soybean and Phakopsora pachyrhizi, the cause of soybean rust. CAB Reviews: Perspective in Agriculture, Veterinary Science, Nutrition and Natural Resources, 6(025), 13. http://doi. org/10.1079/PAVSNNR20116025

Jarvie, J. A (2009). A review of soybean rust from a South African perspective. South African Journal of Science, 105(3/4), 103. http://doi. org/10.4102/sajs.v105i3/4.55

Kato M, Yorinori J T. 2008. A study on a race composition of Phakopsora pachyrhizi in Brazil: a difficulty of race identification. In JIRCAS Working Report No. 58, eds. Kudo, H. et al. JIRCAS, Tsukuba, Japan, 94-98.

Kawuki, R. S., Adipala E., Tukamuhabwa P. 2003. Yield Loss Associated with Soya Bean Rust (Phakopsora pachyrhizi) in Uganda. Journal of Phytopathology, 151(1):7-12. DOI: 10.1046/j.1439-0434.2003.00668.x

Kumudini, S., Godoy, C. V., Board, J. E., Omielan, J., \& Tollenaar, M. (2008). Mechanisms involved in soybean rust-induced yield reduction. Crop Science, 48(6), 2334-2342. http://doi. org/10.2135/cropsci2008.01.0009

Li, X., Dias, a P., Xue, L., Pan, Z., \& Yang, X. B. (2010). Uniqueness of the SBR pathosystem and its scientific value, global distribution, economic importance, and epidemiology of SBR. Plant Disease, 94(7), 796-806. http://doi. org/10.1094/PDIS-94-7-0796

Maphosa, M., Talwana, H., \& Tukamuhabwa, P. (2013). Assessment of Comparative Virulence and Resistance in Soybean Using Field Isolates of Soybean Rust. Journal of Agricultural Science, 5(5), 249-257. http://doi.org/10.5539/jas. v5n5p249

Medeiros, E., Ponte, D., \& Esker, P. D. (2008). Meteo- rological Factors and Asian Soybean Rust Epidemics - A System approach and implications for risk Assessment. Sci. Agric, 65(December), 88-97.

Mueller, T. a., Miles, M. R., Morel, W., Marois, J. J., Wright, D. L., Kemerait, R. C., Hartman, G. L. (2009). Effect of Fungicide and Timing of Application on Soybean Rust Severity and Yield. Plant Disease, 93(3), 243-248. http://doi. org/10.1094/PDIS-93-3-0243

Pham, T. A., Hill, C. B., Miles, M. R., Nguyen, B. T., Vu, T. T., Vuong, T. D., Hartman, G. L. (2010). Field Crops Research Evaluation of soybean for resistance to soybean rust in Vietnam. Field Crops Research, 117(1), 131-138. http://doi. org/10.1016/j.fcr.2010.02.011

Politowski, K., \& Browning, J. (1978). Tolerance and resistance to plant disease: an epidemiological study. Phytopathology, 68(8), 1177-1185. Retrieved from http://www.cabdirect.org/abstracts/19791676201.html

Scafer, J. S. (1971). Tolerance to Plant Disease. Annual Review of Phytopathology, 9, 235-252.

Simko, I., \& Piepho, H. (2012). The Area Under the Disease Progress Stairs : Calculation, Advantage , and Application. Phytopathology, 102(4), 381-389.

Slaminko, T. L., Sciences, C., Miles, M. R., States, U., Frederick, R. D., Bonde, M. R., Hartman, G. L. (2008). New Legume Hosts of Phakopsora pachyrhizi Based on Greenhouse Evaluations. Plant Disease, 92(5), 767-771.

Twizeyimana, M., Ojiambo, P. S., Sonder, K., Ikotun, T., Hartman, G. L., \& Bandyopadhyay, R. (2009). Pathogenic variation of Phakopsora pachyrhizi infecting soybean in Nigeria. Phytopathology, 99(4), 353-361. http://doi. org/10.1094/PHYTO-99-4-0353

Yamanaka, N., Yamaoka, Y., Kato, M., Lemos, N. G., Passianotto, A. L. D. L., Santos, J. V. M. Dos, Suenaga, K. (2010). Development of classification criteria for resistance to soybean rust and differences in virulence among Japanese and Brazilian rust populations. Tropical Plant Pathology, 35(June), 153-162. http://doi. org/10.1590/S1982-56762010000300003 